\title{
Cariology Curriculum in Chilean Universities
}

\author{
Marco Díaz-Yokens ${ }^{1 *}$, Sergio González¹, Rodrigo A Giacaman², Francisca Araya-Bustos², \\ Gustavo Moncada ${ }^{3}$, Stefania Martignon ${ }^{4}$.
}

1. Dental School, Universidad Mayor, Santiago, Chile.

2. Dental Faculty, Universidad de Talca, Talca, Chile.

3. Facultad de Odontología, Universidad de Los Andes, Santiago, Chile.

4. Dental Faculty, Universidad El Bosque, Bogotá, Colombia and King's College Dental Institute, London, UK.

* Corresponding Author: Marco Díaz-Yokens | Cariology, Dental School, Universidad Mayor, Avenida Alameda Libertador Bernardo O'Higgins $N^{\circ}$ 2013, Santiago, Chile. | Phone (+562) 223281783 | E-mail:marco.diazyokens@gmail.com Work received on 10/01/2018. Approved for publication on 21/02/2018

\section{ABSTRACT}

Aim: To describe the current state of undergraduate Cariology teaching in Chilean universities. Material and Methods: A previously content-validated questionnaire was used to conduct a cross-sectional study including all private/public universities. Statistical analysis was performed determining frecuency distributions of categorical variables with the Stata Data Analysis and Statistical Software 13.1®.

Results: Cariology is a key issue in undergraduate education, and in most universities, is taught as key axis of courses, in various departments, for more than one year. Consistency was found in Cariology topics taught. The clinical threshold for surgical treatment is roughly divided into thirds (33.3\% enamel microcavitation, $38.9 \%$ underlying shadow and $27.8 \%$ dentin cavity), no university indicated operative treatment for non cavitated lesions. Radiographic threshold for surgical treatment is the external dentinal third $(66.7 \%)$.

Conclusions: Answers revealed a mix of traditional and modern Cariology concepts. Depite some encouraging results, half of Chilean universities considered that Cariology is not appropriately implemented and no standardization exists between theoretical teaching and clinical management, nonoperative management is not properly clinically implemented, students are evaluated for tissue damage restoration and resistance to non-invasive philosophy adoption remains.

KEYWORDS

Caries; Cariology; Cariology teaching; Cariology learning; Dental education.

Rev. Clin. Periodoncia Implantol. Rehabil. Oral Vol. 11(2); 98-101, 2018.

\section{INTRODUCTION}

Dental caries in permanent teeth is the most prevalent human disease, affecting 2.4 billion people worldwide. In deciduous teeth is one of the most common diseases, affecting 621 million children worldwide ${ }^{(1)}$. Despite the reported prevalence and severity reduction worldwide ${ }^{(2)}$, caries remains a public health issue in most countries, associated with health care access barriers and economic, educational, and social inequalities ${ }^{(1,3)}$. It is also the fourth most expensive chronic disease to treat ${ }^{(1)}$.

Caries understanding shifted from the traditional cavitated lesion concept (advanced destructive disease stage) to being considered a dynamic continuous demineralization-remineralization process clinically manifested once ecological imbalance is established with net mineral loss ${ }^{(4)}$. This can be arrested at any time, mainly in its early stages. Elimination and/or modification of predisposing factors before cavitation can prevent or delay surgical management and subsecuent restoration/ re-restoration cycle and thus operative dentistry then becomes a mean for disease control by removing cariogenic biofilm retention sites ${ }^{(5)}$. The new caries paradigm, concerned with the disease as much as with the resulting lesions, results in the need to change traditional teaching ${ }^{(6)}$.

Chilean dental education began in 1888 at the University of Chile. Until 1995, there were five dental schools in five universities. Multiple dental schools have emerged since then, and now there are 33 dental schools in 21 universities distributed as follows: 15 universities (1 dental school each), 3 universities (2 dental schools each), 1 (3 schools), 1 (4 schools) and 1 (5 dental schools).

The first Cariology teaching study was conducted in North America ${ }^{(7)}$, and similar studies have been conducted in Japan ${ }^{(8)}$, Europe ${ }^{(9)}$, U.S.(10), Spanish-Speaking Latin American Countries (SSLA)(11), and Brazil(12). Between 2010 and 2011, the European Organization for Caries Research (ORCA) and the Association for Dental Education in Europe (ADEE) developed and published a core Cariology curriculum for undergraduate students covering important Cariology aspects ${ }^{(13)}$. It was subsequently reviewed, analyzed, and used as the basis for a core curriculum for undergraduate Colombian ${ }^{(6)}$ and U.S. ${ }^{(14)}$ students. Chile has not proposed nor adopted a core Cariology curriculum. Based on this background and the lack of Chilean-specific studies, the objective of this study is to describe the current state of undergraduate Cariology teaching in Chilean universities. This information will allow for the current situation analysis and national unified curricula improvement proposals.

\section{MATERIAL AND METHODS}

A cross-sectional study was conducted between July 2014 and March 2015 using a 20 item questionnaire designed and previously validated for content in SSLA dental schools by Martignon et al. ${ }^{(11)}$. Questions assessed four Cariology teaching areas: curriculum(7), diagnosis(5), management(7) and perceptions(1).

All public and private universities with dental schools were identified, including those affiliated to the Chilean Association of Dental Teachin (ACHEO, $n=14$ ) and those with websites on the internet up to July 2014 $(n=7)$, totaling 21 universities. Invitation letters were sent via email to Deans or Directors, as was deemed appropriate for each Faculty or Dental School respectively, inviting them to participate in this study along with a brief description of the project. Recipients were asked to provide contact details for Cariology teacher(s) in their Faculty/School, who were then invited to answer the questionnaire via email. Email reminders were sent (up to 4) and participants were also reminded via phone calls. Data was then transferred to an Excel spreadsheet (Microsoft Office, 2010) by an experienced researcher. Another researcher reviewed the data consistency to minimize possibility of errors. Universities with more than one dental school were considered to be one entity, due to the similarity in teaching models reported among all of its schools. Analysis was performed determining frecuency distributions of categorical variables with the Excel software ${ }^{\circledR}$ (Microsoft Office, 2010).

\section{RESULTS}

Completed questionnaires were returned from 18 out of the 21 identified universities, with a response rate of $85.7 \%$.

Cariology Curriculum. To question "Is Cariology teaching at your Faculty/School the axis or part of a course?" $66.7 \%$ answered that is the axis of a course.

To question "Which department/area teaches Cariology at your Faculty/ School?" Operative/Restorative Dentistry was the most mentioned (50\%), followed by Cariology (44.4\%) and Pediatric Dentistry (38.9\%). $55.6 \%$ of 
universities teach in one department/area, while $38.9 \%$ of the universities do it in 2 or more departments.

To question "In which year(s)/semester(s) do students have theoretical Cariology teaching?" $38.9 \%$ teach Cariology during 1 year, $61.1 \%$ for 2 or more years. $16.7 \%$ begin Cariology teaching the first year, $27.8 \%$ start the second year and $50 \%$ the third year.

To question "How many hours per week are the students being taught about Cariology?" $66.7 \%$ expend less than three weekly hours to Cariology teaching and $27.8 \%$ between $4-7$ weekly hours

To question "Which caries textbook is recommended for Cariology teaching at your Faculty/School?" 55.6\% recommended more than one Cariology textbook, $55.6 \%$ recommended just textbooks, while $22.2 \%$ a combination of textbooks and articles. Fejerskov and Kidd textbook (Dental caries: the disease and its clinical management) is used in $72.2 \%$ of universities.

To question "Indicate the topic(s) being taught in your Faculty/School curriculum" $100 \%$ of universities teach theoretical contents about caries classification, etiology, clinical/histological appearance, detection, diagnosis, risk assessment, early caries management and dental hard tissues removal. Behavorial sciences are the less taught topic in their curriculum $(44,4 \%)$ (Table 1$)$

Table 1. Frequency of universities teaching each theoretical topic

\begin{tabular}{|c|c|c|}
\hline THEORETICAL TOPIC & TOTAL & $\%$ \\
\hline Caries classification & 18 & 100 \\
\hline Dental caries etiology & 18 & 100 \\
\hline $\begin{array}{l}\text { Clinical/histological appearance of } \\
\text { carious lesions }\end{array}$ & 18 & 100 \\
\hline Caries detection and diagnosis & 18 & 100 \\
\hline Caries risk Assessment & 18 & 100 \\
\hline $\begin{array}{l}\text { Early caries management } \\
\text { (prevention/arrestment/remineralization) }\end{array}$ & 18 & 100 \\
\hline $\begin{array}{l}\text { Removal of dental hard tissues affected } \\
\text { by caries }\end{array}$ & 18 & 100 \\
\hline $\begin{array}{l}\text { Anatomy and histology of dental hard } \\
\text { tissues }\end{array}$ & 17 & 94,4 \\
\hline $\begin{array}{l}\text { Caries epidemiological description/ } \\
\text { analysis }\end{array}$ & 16 & 88,9 \\
\hline $\begin{array}{l}\text { Caries detection, risk assessment, and } \\
\text { management considerations in young } \\
\text { children }\end{array}$ & 16 & 88,9 \\
\hline $\begin{array}{l}\text { Considerations for caries associated } \\
\text { with restorations }\end{array}$ & 16 & 88,9 \\
\hline Considerations for root caries & 14 & 77,8 \\
\hline Dental erosion & 12 & 66,7 \\
\hline Caries management in populations & 11 & 61,1 \\
\hline Behavioral sciences & 8 & 44,4 \\
\hline
\end{tabular}

To question "Do your students have preclinical practice workshops about theoretical concepts before their first contact with patients?" $77.8 \%$ of universities include preclinical practice.

Caries Diagnosis. To question "Which caries detection method(s) is/ are being taught at your Faculty/School?" $100 \%$ of the universities teach visual techniques and activity assessment, $88.9 \%$ radiographic detection, 83.3\% ICDAS while $22.2 \%$ non radiographic (Fluorescence based) methods (Figure 1).

To question "If caries risk assessment is taught in your Faculty/School, please indicate which risk factors are considered" all universities teach caries risk assessment (Figure 2).

To question "At which clinical visual/tactile severity stage of the lesion does your Faculty/School indicate operative treatment?" $38.9 \%$ of universities teach that operative treatment is indicated when underlying shadow, $33.3 \%$ when enamel microcavitation and $27.8 \%$ when there is dentin exposed cavity. No universities indicate operative treatment in non cavitated lesions.

To question "When do patients have bitewing x-rays taken?" $61.1 \%$ of

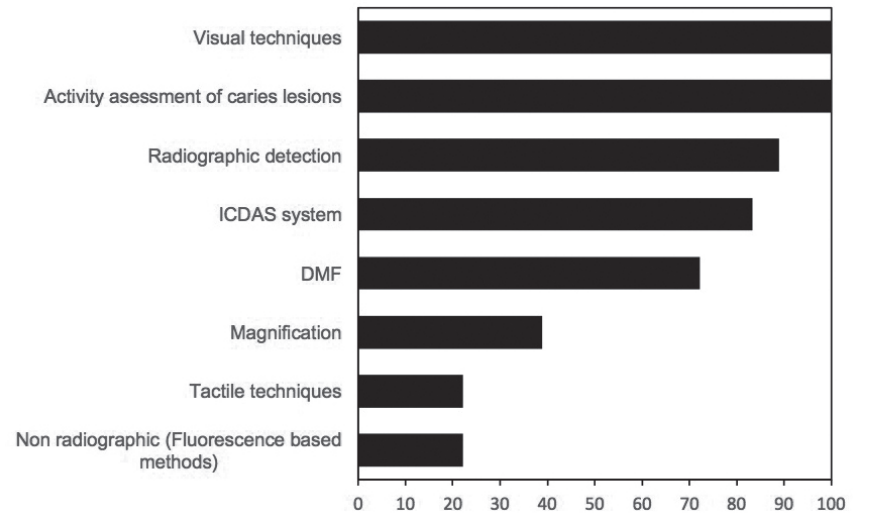

Figure 1. Frecuency (\%) of universities by caries lesion detection method

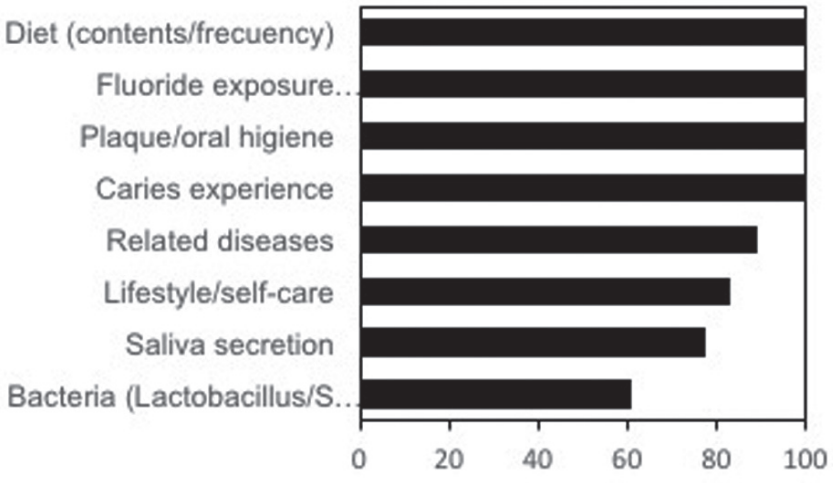

Figure 2. Frequency (\%) of universities by caries risk assessment factor

universities regularly request bite wing $\mathrm{x}$-rays in diagnostic appointment for every patient, $55.6 \%$ for monitoring purposes, $44.4 \%$ depending on the patient's cariogenic risk and $33.3 \%$ to confirm visual/tactile diagnosis.

To question "From what radiolucency depth (caries severity stage) of the lesion does your Faculty/School indicate operative treatment?" $66.7 \%$ teach that operative treatment is indicated when the radiolucent lesion is in the external dentin third, $22.2 \%$ in middle or inner dentin third, and $5.6 \%$ in the inner enamel half and enamel- dentin junction.

Caries Management. To question "If early caries management (caries prevention, arrestment, remineralization) is taught in your Facultyl School, please indicate which topics are considered" more than $90 \%$ of universities teach fluoride, cariogenic diet management, dental sealants and oral hygiene instructions. Calcium and xylitol-based strategies are the less taught topics (Table 2).

To question "How often are non-operative caries management strategies (no bur) being implemented at your Faculty/School clinic?" $55.6 \%$ implement regular non operative caries management strategies, while $44.4 \%$ occasionally. To question "In which way is oral health education communicated to patients being treated at your Faculty/School clinic?" $72.2 \%$ of universities answered that most patients received specific individual oral health education, while $27.8 \%$ received a combination of individual and collective oral health education. To question "How often does the risk assessment drive caries management in the clinical practice of your Faculty/School?" in $66.7 \%$ risk assessment regularly drives caries management and $33.3 \%$ occasionally.

To question "Within caries associated with restorations considerations, does your Faculty/School teach how to repair/reseal restorations as alternatives to operative treatment?" $77.8 \%$ teach to repair/reseal restorations.

To question "Does standardization exist between theoretically taught Cariology and clinical management in your Faculty/School?" $72.2 \%$ answered that there is no standardization. To question "Do you believe Cariology is being taken into account in an appropriate way within your Faculty/School curriculum?" $50 \%$ responded that Cariology is not being taken into account in an appropriate way.

To question "Add any comments on how Cariology is taught at your institution (achievements, shortcomings, improvement proposals, deficiencies, barriers, etc.)" $61.1 \%$ mentioned achievements emphasizing Cariology integration in their curricula and development of multidisciplinary Cariology unit. The $66.7 \%$ mentioned deficiencies or barriers highlighting 
Table 2. Frequency of universities by early caries management topic taught

\begin{tabular}{l|c|c|}
\hline EARLY CARIES MANAGEMENT TOPICS & TOTAL & $\%$ \\
\hline Fluoride & 18 & 100 \\
\hline Cariogenic diet management & 18 & 100 \\
\hline Dental sealants & 17 & 94,4 \\
\hline Oral hygiene instructions & 17 & 94,4 \\
\hline Professional plaque removal & 16 & 88,9 \\
\hline Hyposalivation management & 12 & 66,7 \\
\hline Lesion progression monitoring & 12 & 66,7 \\
\hline pH neutralization strategies & 10 & 55,6 \\
\hline Antibacterial strategies & 9 & 50 \\
\hline Calcium-based strategies & 7 & 38,9 \\
\hline Xylitol-based strategies & 6 & 33,3 \\
\hline
\end{tabular}

the impossibility of ensuring that what they theoretically teach is similar to what is clinically taught and difficulty of implementing conservative measurement strategies in clinical studies because the tendency to evaluate students for restoration of tissue damage.

\section{DISCUSSION}

This is the first Cariology teaching study that includes $85.7 \%$ of Chilean universities. Martignon et al..$^{(11)}$ studied Cariology teaching in SSLA dental schools including four Chilean universities, however, the results were analyzed in a global context, therefore it was not a complete analysis of Chile's situation.

We collected information through a questionnaire, similar to previous reports $(7-11)$. Our response rate $(85.7 \%)$ is high compared to several studies $^{(7-11)}$, providing a representative view of Chile's situation.

Regarding Cariology curriculum, Cariology is recognized as a key issue in undergraduate training in Chile, consistent with other studies ${ }^{(9}$ 11). In $66.7 \%$ of Chilean universities Cariology teaching is the axis of a course, higher than reported in Japan ${ }^{(8)}$, North America ${ }^{(7)}$, Colombia(15), and SSLA ${ }^{(11)}$, but lower than Europe ${ }^{(9)}$ and Brazil(12).

In Chile, as previously reported $(7-9,11,12)$, various departments/areas are responsible for Cariology teaching, predominating individual clinical disease management by restorative/conservative/operative dentistry departments over social/community/public health focus ${ }^{(7-12)}$. Cariology is a field with multiple connections between basic, preclinical and clinical subjects ${ }^{(7,9,12)}$, therefore has traditionally been taught in different courses across the curriculum. No core curricula explicitly recommend that these contents must be taught in an independent Cariology course/department and it has been speculated that an independent course would not be advisable as it may represent a fragmentation/barrier to interdisciplinary teaching-learning promotion and generate a sense of lack of accountability in teachers not directly involved in the issue ${ }^{(12)}$.

Time devoted to Cariology teaching varies, however, workload must be carefully analyzed. Questionnaire responses by Cariology teachers, as mentioned in other studies ${ }^{(7-11)}$, does not allow the quantification of total hours devoted to different Cariology topics in other courses, nor differentiate between theoretical, preclinical, or clinical hours ${ }^{(12)}$.

Eleven of the 15 theoretical topics highly matched in Chilean universities (Table 1), similar to SSLA ${ }^{(11)}$. Dental erosion is less frecuently taught in Chile and SSLA ${ }^{(11)}$ than Europe ${ }^{(9)}$. While ORCA ADEE ${ }^{(13)}$ and U.S. core curricula(14) includes dental erosion, given its particular pathogenesis and clinical manifestations, its inclusion as part of Cariology is questionable. In Chile, the less frequently taught subjects are caries management in populations and behavioral sciences. It is noteworthy that despite the consensus on the importance of caries prevention, behavioral sciences are not incorporated to a greater extent as undergraduate topic.

Inclusion of preclinical practices in Chilean universities is similar to previous U.S. ${ }^{(10)}$ and SSLA reports ${ }^{(11)}$; however, given the questionnaire characteristics, it is not possible to determine the type of activities undertaken. It has been suggested that, for generations, students used their preclinical work to learn stereotypical preconceptions of caries invasive management in natural or artificial teeth, therefore it seems advisable to analyze the activities and their effect on the expected competencies development throughout the curriculum.

Regarding caries diagnosis, the carious lesion detection methods most frequently taught worldwide are the visual/visual-tactile and radiographic methods ${ }^{(7,8,11)}$. All Chilean universities taught visual detection method and lesion activity assessment. ICDAS is taught more frecuently than U.S. ${ }^{(10)}$ and SSLA ${ }^{(11)}$. It should be noted that these responses can range from mere theoretical instruction to clinical implementation. Tactile method is the least commonly taught method in Chile, consistent with the recommendation to avoid the use of explorer for primary lesions detection, given the inherent risks and limited contribution to diagnostic accuracy ${ }^{(16)}$.

All Chilean universities teach cariogenic risk assessment, similar to the U.S. ${ }^{(10)}$ and SSLA ${ }^{(11)}$. The least taught risk factors are salivary secretion and specific bacteria such as Lactobacillus and S. mutans; the latter can be explained by the adoption of ecological plaque theory over specific plaque theory.

A wide variation in surgical treatment threshold has been reported ${ }^{(10)}$. When inquiring about the carious lesions clinical severity stage threshold in Chile, no university indicated operative treatment of white/coffee spot lesions. One-third of Chilean universities taught to use surgical treatment for microcavitation (loss of enamel surface integrity), similar than reported in SSLA $^{(11)}$, which is associated to traditional caries management approach. There is a growing consensus that these lesions require a comprehensive individual assessment and, depending on the lesion activity, radiographic depth and patient cariogenic risk, many of them can be non-invasively (biologically) managed. The questionnaire does not allow the determination of whether the proposed operative treatment is microinvasive, minimally invasive, nor invasive.

Sixtyone percent of Chilean universities taught to regularly request bitewing X-Rays in diagnostic appointment for every patient. Considering the legal requirement of avoiding patient exposure to unnecessary radiation, and radiograph prescription must be based on individual assessment, we think that initial radiological examination for all patients is an error as it contributes to, but does not replace thorough clinical examination.

Regarding radiographic threshold, one Chilean university indicates operative treatment when the radiolucency is between middle enamel and enamel-dentin junction, lower than reported in SSLA ${ }^{(11)}$, while two thirds of Chilean universities indicate surgical treatment when radiolucent lesions in the dentin outer third, similar than reported in North America ${ }^{(7)}$ and Japan ${ }^{(8)}$. Restorative treatment must be indicated when lesions are cavitated, given the impossibility of achieving good hygiene and biofilm metabolism change ${ }^{(17)}$. X-rays cannot identify cavitation. It has been reported that in inner enamel half lesions, only $10.2 \%$ are cavitated ${ }^{(18)}$, in the outer dentin third, $32 \%$ are cavitated ${ }^{(19)}$ and in the inner dentin half, $41 \%$ are cavitated ${ }^{(18)}$. This limits operative treatment indication based exclusively on radiographic images.

Concerning caries management, all Chilean universities teach prevention, arrestment and remineralization of early lesions. Professional removal of plaque, oral hygiene instruction, use of fluorides, dental sealants, and cariogenic diet management are taught in more than $90 \%$ of Chilean universities. Nevertheless they are regularly implemented in slightly more than half of them, showing discrepancy between topics theoretically taught and clinically implemented .

Hyposalivation management and $\mathrm{pH}$ neutralization strategies are taught in between $50-70 \%$ of Chilean universities, similar to previous reports from U.S. ${ }^{(10)}$ and SSLA ${ }^{(11)}$. Xylitol based strategies, taught by more than $80 \%$ of U.S. dental schools ${ }^{(10)}$, are taught in a few Chilean and SSLA universities (Table 2$)^{(11)}$. Additionally, $50 \%$ of Chilean universities taugth antibacterial strategies, less than reported in SSLA ${ }^{(11)}$

Even though more than half of Chilean universities regularly implement nonoperative caries management strategies in clinical practice and two thirds of Chilean universities plan dental treatment based on cariogenic risk on a regular basis, higher than reported for SSLA ${ }^{(11)}$, a high percentage of universities still adhere to traditional "old-fashioned" caries management. Data suggests, consistent with previous reports ${ }^{(11,20)}$, that non-invasive measurements are not properly implemented in clinical teaching, although they are theoretically taught.

Approximately $80 \%$ of Chilean universities teach students to repair/ reseal restorations, higher than reported for SSLA ${ }^{(11)}$, Japan ${ }^{(8)}$ and North America $^{(21)}$. Given multiple described advantages for this procedure 
(e.g. dental tissue preservation, increased restoration longevity, good patient acceptance and lower pulp damage risk, pain, iatrogenic damage to adjacent teeth, time and cost of treatment)(22), it seems advisable to include it in the curriculum, carefully considering its indications and technical procedure.

Questionnaire answers regarding curriculum, diagnosis, and treatment reveal a mix of traditional and modern Cariology concepts and suggest efforts to adopt the new paradigm ${ }^{(23)}$. It is important to highlight, that these results correspond to theoretical aspects. Half of Chilean universities considered that Cariology is not appropriately implemented in their curricula, and almost two thirds answered that no standardization exists between theoretical teaching and clinical management, higher but consistent with previous reports $(10,11,20,24)$. This is probably because nonoperative management is not encouraged nor properly evaluated as a clinical activity in undergraduate curricula $(15,20,24)$, and students are still evaluated for tissue damage restoration (issue not studied in this questionnaire). Moreover, some clinicians still show resistance to noninvasive philosophy adoption ${ }^{(7,15,20,24)}$. We think these reasons explain why students have difficulties to learn these important issues and delay the acceptance of the new caries paradigm. Standardized education seems relevant in establishing a knowledge base among undergraduates $^{(13)}$, as well as adopting a core curriculum based on the best available evidence ${ }^{(25)}$.

These results will allow the revision and improvement of current curricula. Also, future educational studies should assess the implementation and learning outcomes of those curriculum changes.

\section{CONCLUSIONS}

This is the first Cariology teaching description that includes all Chilean universities. It identifies strengths and weaknesses in the Cariology Curricula in Chile. Answers revealed that while Cariology is a key issue in undergraduate education, a mix of traditional and modern concepts is being taught. Furthermore, while nonoperative management with a multifactorial approach is theoretically taught in all universities, it is not properly clinically implemented nor treatment planning based on individual risk. Future studies should evaluate how this could be changed and implemented across the university system.

\section{DISCLOSURE}

The authors confirm no conflicts of interest.

\section{ACKNOWLEDGMENTS}

Dr. Mónica Quintana for her help contacting Faculty Deans/Dental School Directors.

\section{References}

1. Kassebaum N, Bernabé E, Dahiya M et al. Global Burden of Untreated Caries: A Systematic Review and Metaregression. J Dent Res 2015;94(5):650-658.

2. Petersen PE, Bourgeois D, Ogawa $\mathrm{H}$ et al. The global burden of oral diseases and risks to oral health. Bull World Health Organ 2005;83(9):661-9.

3. Ismail A, Sohn W. The impact of universal access to dental cares on disparities in caries experience in children. J Am Dent Assoc 2001;132(3):295-303.

4. Fejerskov O, Larsen MJ. 2015. Demineralization and remineralisation: the key to understanding clinical manifestations of dental caries. In: Fejerskov O, Nyvad B Kidd E, eds. Dental caries: the disease and its clinical management. Oxford (UK): Wiley Blackwell. 2015:155-170.

5. Anderson MH, Bales DJ, Omnell KA. Modern management of dental caries: the cutting edge is not the dental bur. J Am Dent Assoc. 1993;124(6):36-44.

6. Martignon S, Marín LM, Pitts N, Jácome-Liévano S. Consensus on domains, formation objectives and contents in cariology for undergraduate dental students in Colombia. Eur J Dent Educ 2014;18:222-233.

7. Clark TD, Mjör IA. Current teaching of cariology in North American dental schools Oper Dent 2001;26(4):412-8.

8. Fukushima M, Iwaku M, Mjör I. Cariology in Japanese Dental Schools. Int Dent J. 2004;54(5):269-72.

9. Schulte AG, Buchalla W, Huysmans MC et al. A survey on education in cariology for undergraduate dental students in Europe. Eur J Dent Educ 2011;15(Suppl 1):3-8. 10. Fontana M, Horlak D, Sharples S et al. Teaching of cariology in U.S. dental schools. J Dent Res 2012;91(Spec Iss A):Abstract 313

11. Martignon S, Gomez J, Tellez M et al. Current Cariology Education in Dental Schools in Spanish-Speaking Latin American Countries. J Dent Educ 2013;77(10):1330-37.

12. Ferreira-Nóbilo N, de Sousa M, Cury JA. Cariology in Curriculum of Brazilian Dental Schools. Braz Dent J 2014;25(4):265-70.

13. Schulte AG, Pitts NB, Huysmans MC et al. European Core Curriculum in Cariology for Undergraduate Dental Students. Caries Res 2011;45:336-345.
14. Fontana M, Guzman-Armnstrong S, Schenkel $A B$ et al. Development of a Core Curriculum Framework in Cariology for U.S. Dental Schools. J Dent Educ 2016;80(6):705-720

15. Martignon S, Otalvaro-Castro GJ, Ochoa EM et al. Embracing the new caries paradigm among Colombian dental schools. J Dent Res 2012;91(Spec Iss B):1141. 16. Ekstrand K, Qvist V, Thylstrup A Light microscope study of the effect of probing in occlusal surfaces. Caries Res 1987;21:363-374.

17. Pitts NB. Detection, assessment, diagnosis, and monitoring of caries. Monographs in Oral Science, Vol. 21. Basel, Switzerland: Karger AG, 2009.

18. Pitts NB, Rimmer PA. An in vivo comparison of radiographic and directly assessed clinical caries status of posterior approximal surfaces in primary and permanent teeth. Caries Res. 1992;26(2):146-52.

19. Hintze $H$, Wenzel A, Danielsen B, Nyvad B. Reliability of visual examination, fibre-optic transillumination, and bite-wing radiography, and reproducibility of direct visual examination following tooth separation for the identification of cavitated carious lesions in contacting approximal surfaces. Caries Res. 1998:32(3):204-9.

20. Ochoa EM, Jacome-Lievano S, Otalvaro GJ et al. Curricular-perspective analysis: opportunities \& problematics in the new caries paradigm in Colombian dental schools. Caries Res 2012;46:Abstract 45.

21. Gordan VV, Mjör IA, Blum IR, Wilson N. Teaching students the repair of resinbased composite restorations: a survey of North American dental schools. J Am Dent Assoc. 2003;134(3):317-23.

22. Blum IR, Jagger DC, Wilson $\mathrm{HH}$. Defective dental restorations: to repair or not to repair? Part 1: direct composite restorations. SADJ. 2011;66(3):114-8.

23. Fejerskov $\mathrm{O}$. Changing paradigms in concepts on dental caries: consequences for oral health care. Caries Res 2004;38:182-91.

24. Jácome-Liévano S, Marín LM, Ochoa AM et al. Cariology-teaching in Colombia: Contrast of a workshop and a questionnaire. J Dent Res 2012;91(Spec Iss B):1140. 25. Plasschaert AJ, Holbrook WP, Delap E et al. Profile and competences for the European dentist. Eur J Dent Educ 2005;9(3):98-107. 